\title{
The Simulation and Experiment of a Non-Cross-Feeding Printed Log-Periodic Antenna
}

\author{
Chun-Ying Kang, ${ }^{1}$ Shu Lin, ${ }^{2}$ Zhi-Hua Zhao, ${ }^{3}$ and Li-Wen Jing ${ }^{3}$ \\ ${ }^{1}$ School of Information Science and Technology, Heilongjiang University, Harbin 150080, China \\ ${ }^{2}$ Center for Control Science and Engineering Post-Doctoral Studies, Harbin Institute of Technology, Harbin 150080, China \\ ${ }^{3}$ School of Electronics and Information Engineering, Harbin Institute of Technology, Harbin 150080, China \\ Correspondence should be addressed to Shu Lin; linshu@hit.edu.cn
}

Received 28 October 2014; Revised 24 March 2015; Accepted 27 March 2015

Academic Editor: N. Nasimuddin

Copyright (C) 2015 Chun-Ying Kang et al. This is an open access article distributed under the Creative Commons Attribution License, which permits unrestricted use, distribution, and reproduction in any medium, provided the original work is properly cited.

\begin{abstract}
A non-cross-fed printed log-periodic antenna is simulated and studied experimentally. To avoid complex feeding with long coaxial line, the non-cross-feeding structure is applied in this antenna. The software CST Microwave Studio is employed to simulate the proposed antenna, and the optimized antenna model is obtained. According to the simulation results, the antenna prototype is produced and measured. Simulation and measured results show that the antenna is with $\left|S_{11}\right|<-10 \mathrm{~dB}$ in band of $4.2-9.2 \mathrm{GHz}$. And the radiation pattern and gain vary steadily in this band, which achieves requirements for wideband antenna. This antenna design can be extended to the design of the antenna integrated in communication circuit.
\end{abstract}

\section{Introduction}

With the development of communication technology, demands for the antenna specifications grow increasingly. To improve transmission speed, the employed antenna should have broad band. Besides, steady phase center is also required for transmitting time-domain signal at an UWB spectrum. In other words, the antenna should be a miniaturization [1]. To increase communication distance, the high-gain characteristic is needed [2]. In most cases, antenna should have such characteristics as small size, light weight, and low profile to make more convenient integration with circuit of communication system [3]. Printed antenna, which is based on printed board, can satisfy all the requirements above. Besides, the printed substrate can also make some beneficial influences for the antenna performance. For example, as the increasing electromagnetic energy density can enhance coupling, the bandwidth of antenna can be broadened [4]. Focusing effect of substrate can also make a higher gain $[5,6]$. Some kinds of feeding structure which make integration easier can also be introduced, such as microstrip line [7], balanced microstrip line $[8,9]$, and substrate integrated waveguide $[10]$.
There exist a series of log-periodic dipole antennas without introducing long coaxial feeding line, which can help to make the antenna easily integrated. Abdo-Sanchez et al. had proposed a log-periodic dipole antenna radiated by slots. Working frequency band of $2.7-8.7 \mathrm{GHz}$ and efficiency of $85 \%$ are achieved. However, the directional radiation requested introducing reflector, which would definitely break planar construction of antenna [11]. Koch-shaped dipoles together with closely coupled parasitic elements as directors were utilized for compactness in size and improvement in front-to-back ratio (F/B ratio). However, such design is only suitable for RFID system. The working bandwidth is narrow for $17.7 \%(820-980 \mathrm{MHz})$ [12]. A printed LPDA fed by a coplanar waveguide was proposed. Coplanar waveguide was used to replace coaxial line. Wide working band $(3-6 \mathrm{GHz})$ was obtained. However, the axial dimension was relatively large [13].

A series of printed log-periodic antennas were proposed [14], and all of them are evolved from traditional log-periodic dipole antennas. Cross-feeding structure was adopted, which feeds on one side of short dipole so as to introduce a long 


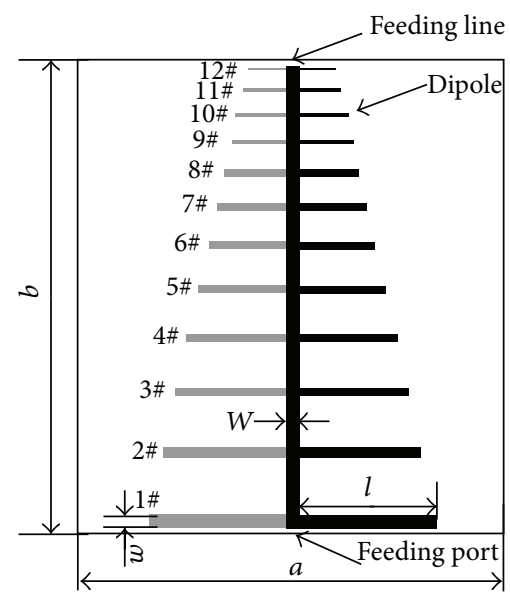

Top view

Bottom view

FIGURE 1: Design of proposed antenna with numbered dipoles of 1-12 from the bottom up.

coaxial feeding line. Therefore, such feeding structure is disadvantageous for being integrated. In this paper, a noncross-feeding printed log-periodic dipole antenna (LPDA) is proposed. The antenna is fed by balanced microstrip. Feeding on one side of long dipole can avoid introducing overlong coaxial feeding line. The software CST Microwave Studio is used to simulate the proposed antenna to get an optimization model. A prototype antenna has also been measured. The simulation and experiment results show that the operating bandwidth is $4.2-9.2 \mathrm{GHz}$ with $\left|S_{11}\right|<-10 \mathrm{~dB}$ and the ratio band can achieve $2.2: 1$. Besides, the in-band gain of antenna varies steadily $(6.0-8.5 \mathrm{dBi})$. The detailed simulation and experiment results can be shown as follows.

\section{Antenna Structure}

Figure 1 shows the structure chart of proposed antenna. Structure of double-sided printed circuit board is adopted. Colorful area stands for the metal layer printed on dielectricslab. The proposed antenna has 12 pairs of dipole, feeding on one side of the long dipole. Besides, waveguide port was introduced in simulation as well as the SMA coaxial connector in experiment.

\section{Design Process and Simulation Result}

The antenna model is set up in the software CST Microwave Studio. The modeling process is as follows: first of all, major parameters should be confirmed, including $W, N, l, \sigma$, and $\tau$; refer to Table 1 . Then, initial values of major parameters above can be calculated by $(1)[15,16]$. They are traditional parameter calculation equation for LDPA, whose results can be introduced as initial values. Because the proposed antenna is different from the traditional one, the final parameters should be confirmed by much simulation and calculation. The parameters obtained finally are listed in Table 1 . Consider
TABLE 1: Optimization results of antenna parameters.

\begin{tabular}{lc}
\hline Parameter & Value \\
\hline Length of dielectric-slab $a$ & $40 \mathrm{~mm}$ \\
Height of dielectric-slab $b$ & $56 \mathrm{~mm}$ \\
Thickness of dielectric-slab $h$ & $1 \mathrm{~mm}$ \\
Relative dielectric constant of dielectric-slab $\varepsilon_{r}$ & 4.4 \\
Width of feeding line $W$ & $1.2 \mathrm{~mm}$ \\
Number of dipoles $N$ & 12 \\
Interleave factor $\sigma$ & 0.15 \\
Scale factor $\tau$ & 0.89 \\
Length of the longest dipole $l$ & $13.4 \mathrm{~mm}$ \\
Width of the longest dipole $w$ & $0.8 \mathrm{~mm}$ \\
\hline
\end{tabular}

$$
\begin{gathered}
\tau=\frac{l_{n}}{l_{n-1}}=\frac{w_{n}}{w_{n-1}} \\
\sigma=\frac{d_{n}}{4 l_{n}} \\
l_{1}=\frac{c}{4 f_{\min } \sqrt{\varepsilon_{e}}} \\
\varepsilon_{e}=\frac{\varepsilon_{r}+1}{2}+\frac{\varepsilon_{r}+1}{2} \cdot \frac{1}{\sqrt{1+12 h / w_{1}}} .
\end{gathered}
$$

Figures 2 and 3 have given the simulation results of reflection coefficient and radiation pattern of proposed antenna. The simulation results indicate that the operating band is 4.2-9.5 GHz. In this working band, its radiation also satisfies directional radiation with gain of 6.3-9.7 $\mathrm{dBi}$. Compared to the traditional LPDA, the bandwidth of proposed antenna is lower. However, it can also have wideband characteristics. In other words, it achieves the impedance and the pattern bandwidth of more than $2: 1$. According to the simulated 


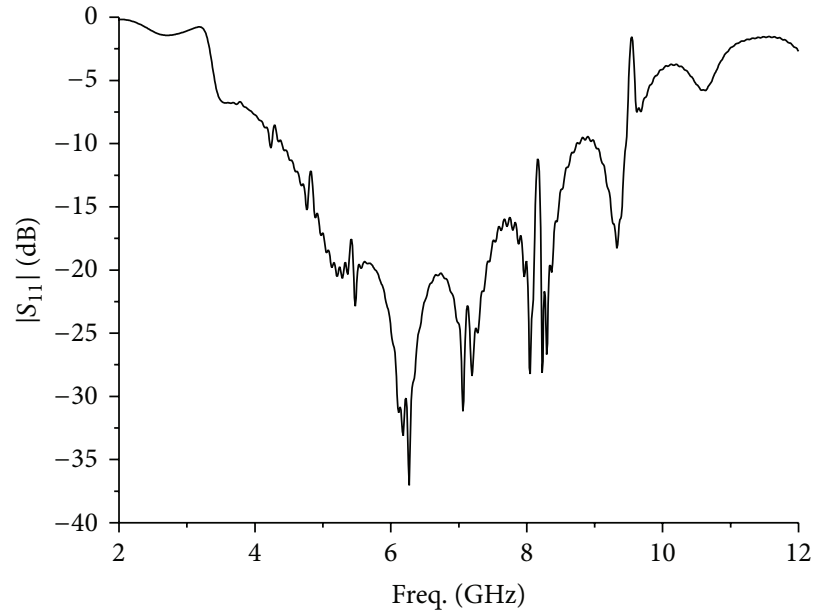

FIGURE 2: Simulation result of reflection coefficient.

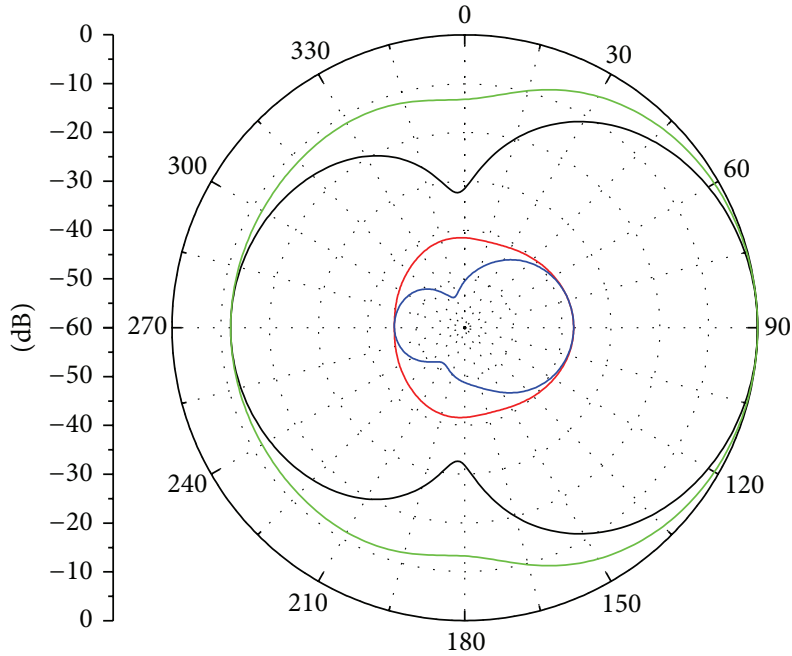

(a) $4.2 \mathrm{GHz}$

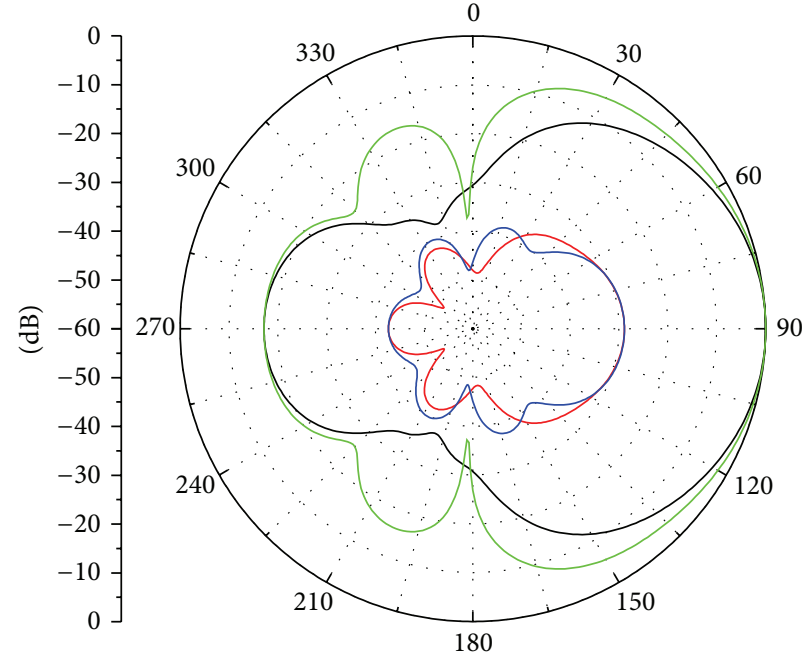

(b) $6.5 \mathrm{GHz}$

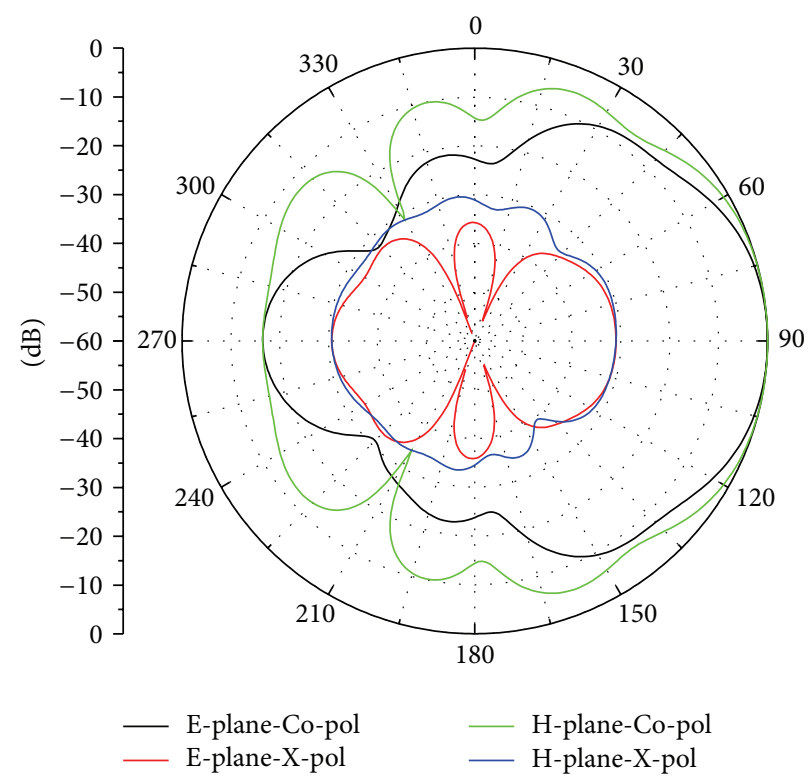

(c) $9 \mathrm{GHz}$

FIGURE 3: Simulation results of radiation pattern. 


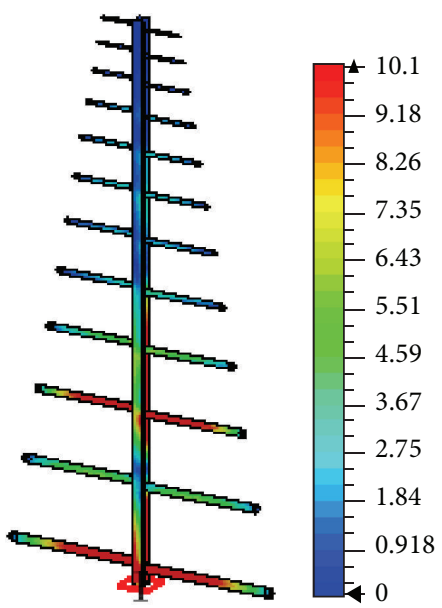

(a) $4.2 \mathrm{GHz}$

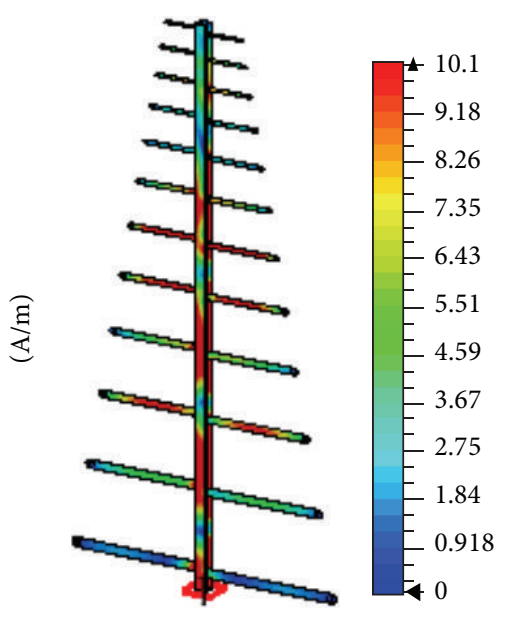

(b) $6.5 \mathrm{GHz}$

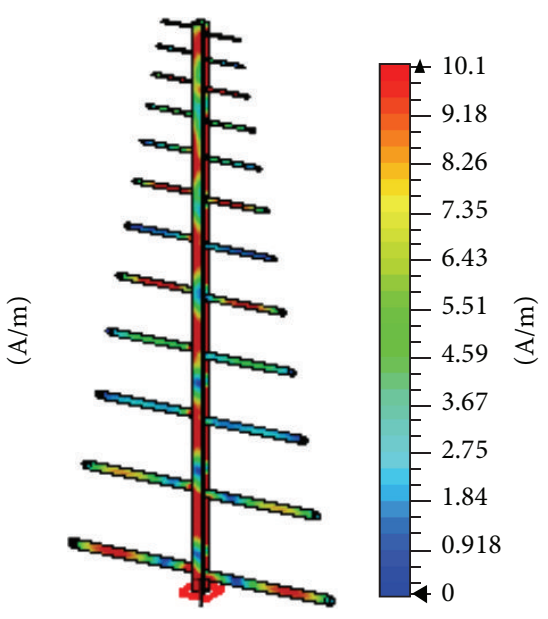

(c) $9 \mathrm{GHz}$

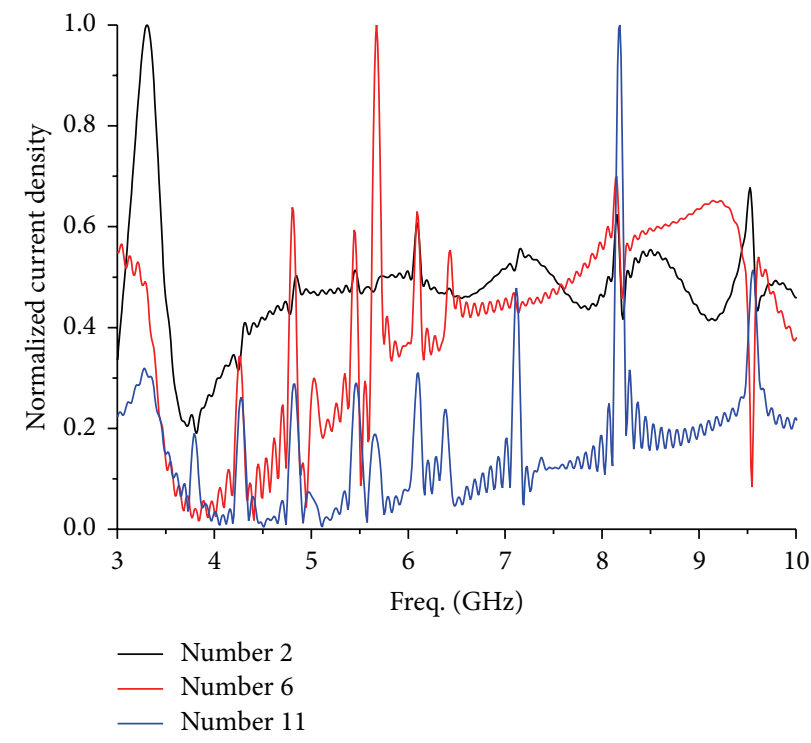

(d) Normalized current densities on the intersections by feeding line with three dipoles

FIGURE 4: Currents densities of proposed antenna.

cross polarization radiation pattern, the cross polarization discrimination within main lobe is higher than $30 \mathrm{~dB}$.

Generally, LPDA adopts cross-feeding way, feeding on one side of short dipole. Feeding line is divided into three parts: transmission area, radiation area, and unexcited area. Advantages of such feeding way are as follows. (1) High-frequency electromagnetic wave radiates by short dipole immediately when it enters the feeding line, and its radiation efficiency is much higher. (2) Bandwidth of antenna is wide with a normal ratio band of $10: 1$. However, it needs a long coaxial line to feed along the feeding line from long dipole to the short one, which is disadvantageous for integration.

The proposed non-cross-fed LPDA is fed directly from long dipole, which could avoid introducing overlong coaxial line and make the integration easier. But, feeding on long dipole also leads to some negative effects. (1) Because of the strong radiation characteristic of high-frequency electromagnetic wave, it radiates immediately when it enters the port of long dipole. Therefore, the antenna efficiency will decline. (2) Along with the flowing current, phases lag gradually. By lacking the regulation of additional $\pi$ phase, which is produced by cross-feeding, the frequency stability of phase difference between different dipoles will be bad. It will decrease the bandwidth of antenna. Even so, the proposed antenna can achieve impedance and pattern bandwidth of more than $2: 1$. Therefore, requirements of mobile communications within close range can be met.

\section{Characteristic Analysis}

For illustrating the working principle of proposed antenna, surface currents are studied by simulation. According to the simulation results of metal parts in frequencies of $4.2 \mathrm{GHz}$, $6.5 \mathrm{GHz}$, and $9 \mathrm{GHz}$, currents of different frequencies will be radiated by different parts of antenna (Figures 4(a) 4(c)). Quantitative analysis can be made in Figure 4(d). 


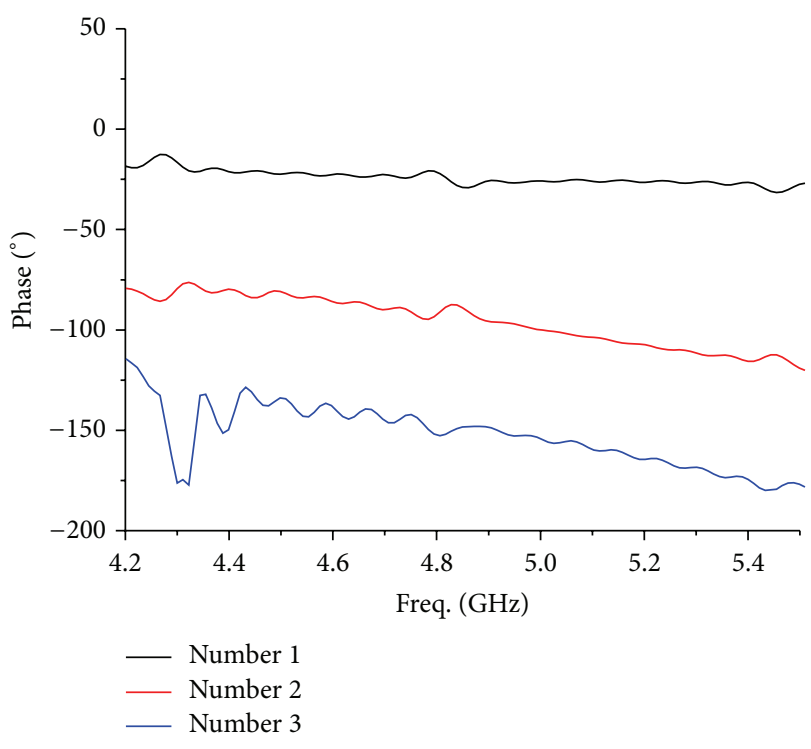

(a) 1st-3rd dipoles $(4.2-5.5 \mathrm{GHz})$

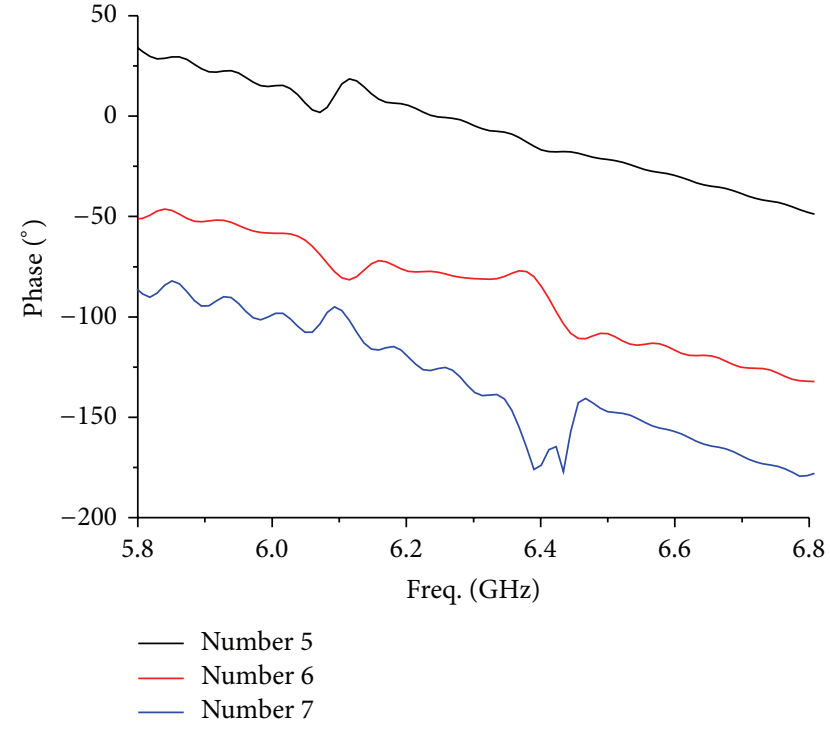

(b) 5 th-7th dipoles $(5.8-6.8 \mathrm{GHz})$

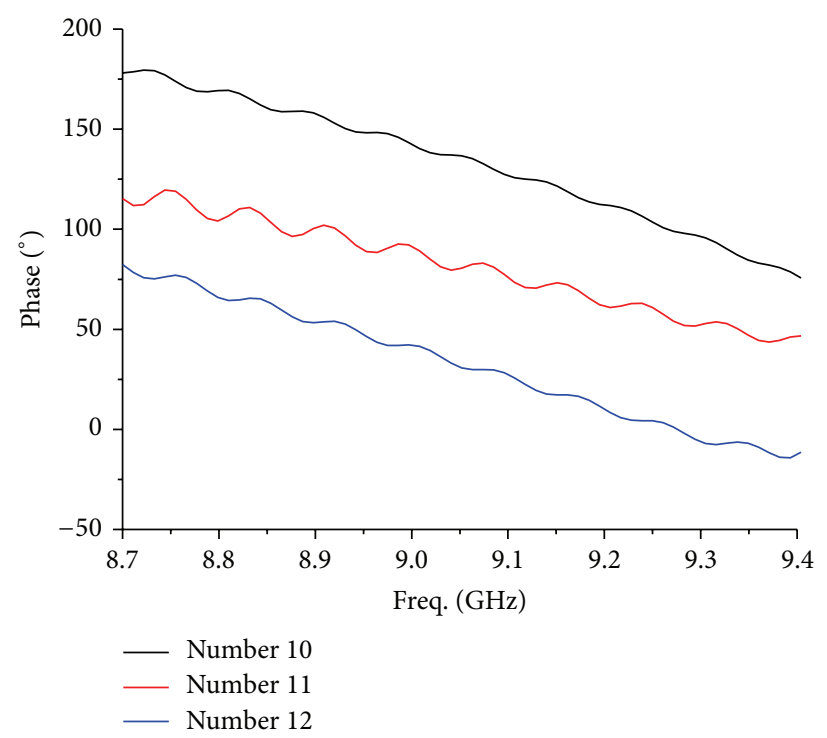

(c) 10th-12th dipoles $(8.7-9.4 \mathrm{GHz})$

FIGURE 5: Phase of each dipole in corresponding band.

With the software CST Microwave Studio, the surface current densities (Figure 4) of node places at the feeding line with 2nd, 6th, and 11th dipole are acquired. Figure 4 shows that all these three dipoles possess their own maximum current densities, whose corresponding frequencies are $3.30 \mathrm{GHz}$, $5.67 \mathrm{GHz}$, and $8.18 \mathrm{GHz}$, respectively. It indicates that each dipole has a resonant frequency. By selecting proper antenna structure parameters, it can make these resonant frequencies achieve stagger tuning. Thus, proposed antenna could obtain wide band.

Figure 5 shows the current density phases of node places at feeding line with 1st-3rd, 5th-7th, and 10th-12th dipoles. 1st-3rd dipoles can be picked, for example. The current densities on these three intersections turn lag in wide band
$(4.2-5.5 \mathrm{GHz})$. It indicates that the antenna array made by three dipoles will achieve directional radiation. The radial direction points to the short dipole. The antenna radiation in this band is mainly decided by 1 st-3rd dipoles. The radiation produced by the other dipoles' weak currents can be ignored. The analysis in the other band is similar to the 1st-3rd dipoles' analysis. The explanation above can well account for characteristic of directional radiation.

\section{Measured Result}

According to parameters obtained by simulation, antenna prototype is produced (Figure 6) and measured in $6.0 \mathrm{~m} \times$ $6.0 \mathrm{~m} \times 8.0 \mathrm{~m}$ microwave chamber by Agilent E8363B Vector 


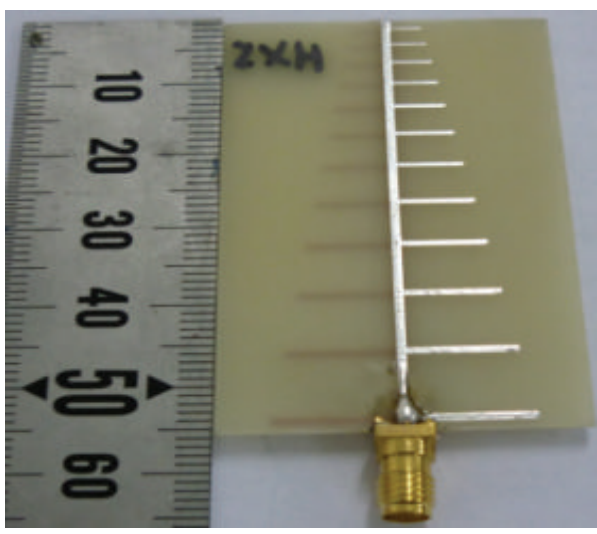

(a) Top view

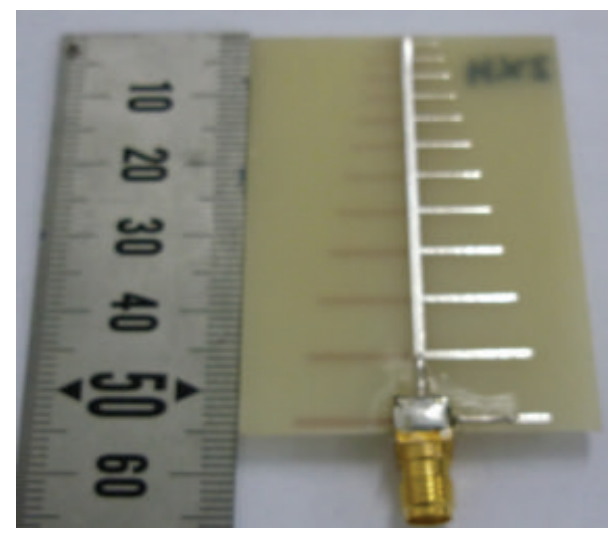

(b) Bottom view

FIGURE 6: Prototype antenna.

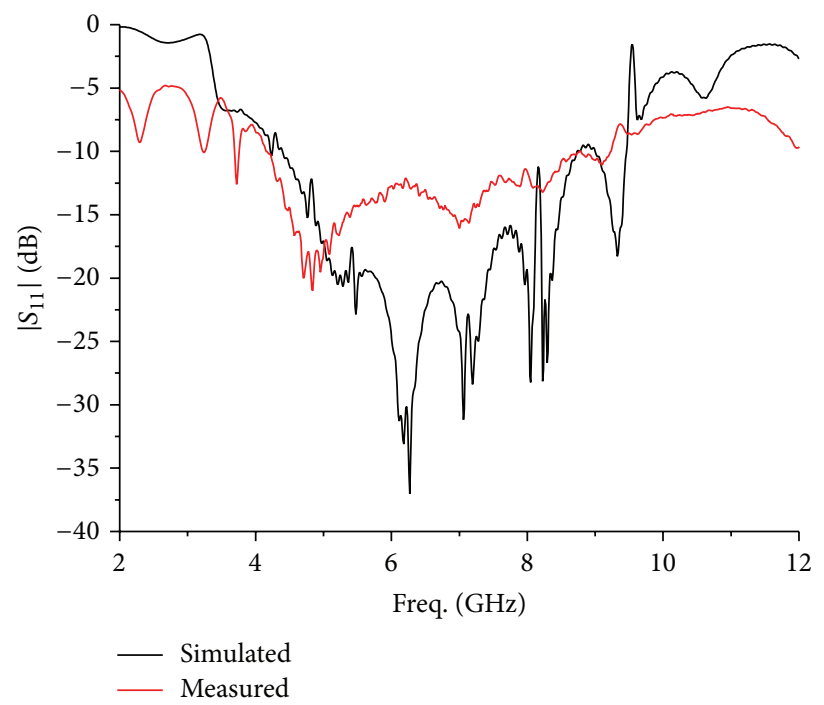

Figure 7: Measured result of reflection coefficient.

Network Analyzer. The measured contents include reflection coefficient, radiation pattern, and gain. The measured results (Figures 7, 8, and 9) indicate that the operating bandwidth is $4.2-9.2 \mathrm{GHz}$ with $\left|S_{11}\right|<-10 \mathrm{~dB}$, which differs little from the simulated result of $4.2-9.5 \mathrm{GHz}$. The measured gain is $1 \mathrm{~dB}$ less than the simulated one. The measured radiation pattern also differs little from the simulated one in main lobe; meanwhile, it differs a lot in side lobe. On the whole, the proposed antenna meets the qualification of wide band antenna. The reasons why the measured results differ a lot from the simulation one are as follows. (1) Dielectric-slab is the normal FR-4 epoxy board with great loss. Its loss tangent is about $10^{-2}$ magnitude, which is more than the common Rogers series material $\left(10^{-3}\right.$ magnitude). The energy loss caused by it will make a decrease of reflection coefficient and gain. (2) The influence from welding and fixture when measuring radiation pattern will affect the measured result of side lobe level. Besides, the instability of FR-4 material will also affect the measured result of antenna radiation pattern.
In the production of antenna prototype, it needs attention for the feeding balance-unbalance transformation of SMA coaxial connector. The way to weld the SMA connector is depicted in Figure 6. Welding spot of coaxial connector and feeding line can be regarded as a small floor, which forms a quasi microstrip line with another spot. Then, the feeding structure of printed log-periodic antenna is coaxial line-quasi microstrip line-feeding line (balanced microstrip), which could balance the feeding.

\section{Characteristics of Proposed Antenna}

In order to illustrate the significance of proposed antenna, the compared performances between proposed antenna and the ones in reference are listed in Table 2. For the unification of the antenna working in different working band, the concept of electrical size has been introduced. Electrical size is the ratio of the maximum size of antenna and the wavelength corresponding to the lowest working frequency, calculated 


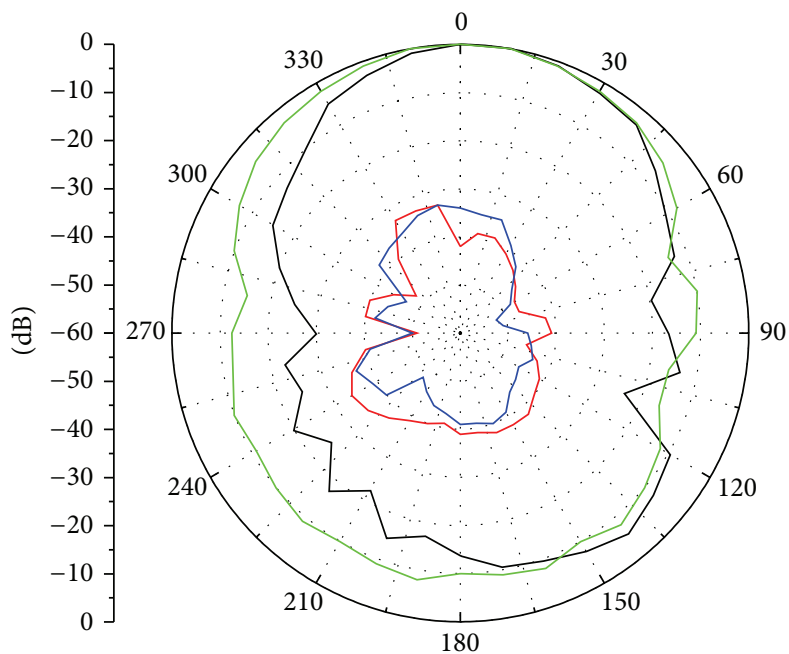

(a) $4.2 \mathrm{GHz}$

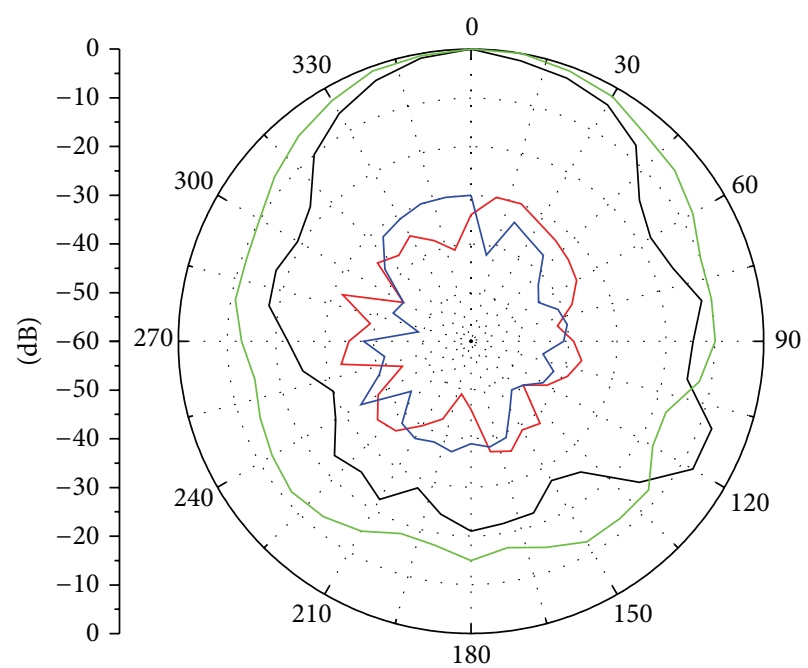

(b) $6.5 \mathrm{GHz}$

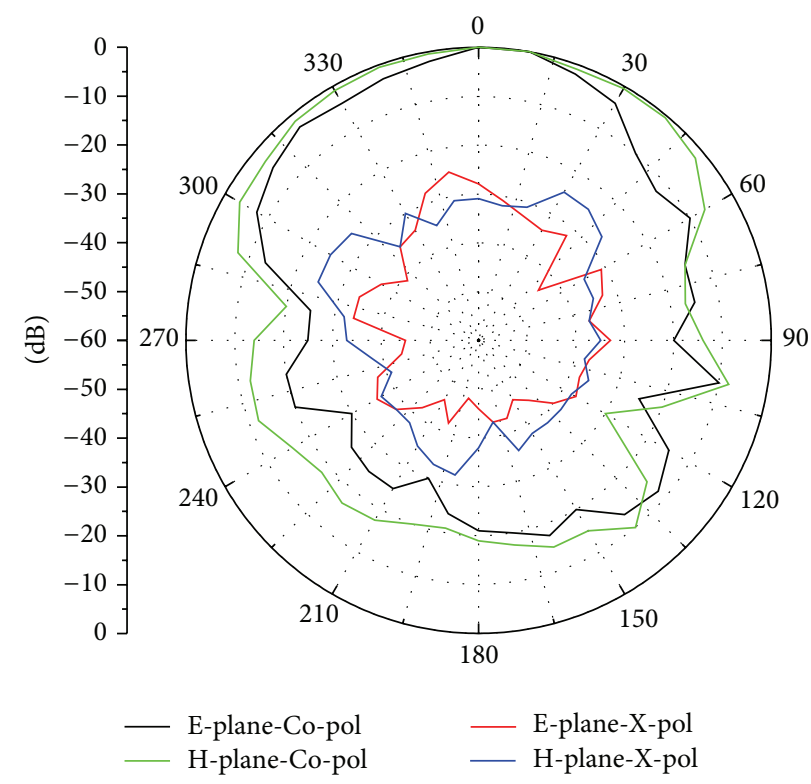

(c) $9 \mathrm{GHz}$

FIGURE 8: Measured result of radiation pattern.

TABLE 2: Comparison between the proposed antennas and the ones in reference.

\begin{tabular}{lcccc}
\hline Antenna type & Operating frequency band & Gain & Size & Electrical size \\
\hline Proposed antenna & $4.2-9.2 \mathrm{GHz}$ & $6.0-8.5 \mathrm{dBi}$ & $56 \mathrm{~mm} \times 40 \mathrm{~mm}$ & $0.78 \times 0.56$ \\
Reference [11] & $2.7-8.7 \mathrm{GHz}$ & $5 \mathrm{dBi}$ & $184 \mathrm{~mm} \times 100 \mathrm{~mm}$ & $1.66 \times 0.9$ \\
Reference [13] & $3-6 \mathrm{GHz}$ & $5.0-7.5 \mathrm{dBi}$ & $117 \mathrm{~mm} \times 76 \mathrm{~mm}$ & $1.17 \times 0.76$ \\
\hline
\end{tabular}

by (2). It can be seen that the characteristics of proposed antenna are wide band, high gain, and small dimensions relatively. Consider

$$
l_{e}=\frac{l}{\lambda_{\max }} .
$$

\section{Conclusion}

A non-cross-fed printed log-periodic antenna is proposed. By much simulation, its optimal parameters are acquired. According to the data obtained by simulation, its characteristics of wide band and directional radiation are illustrated. The antenna prototype is also produced for measuring. 


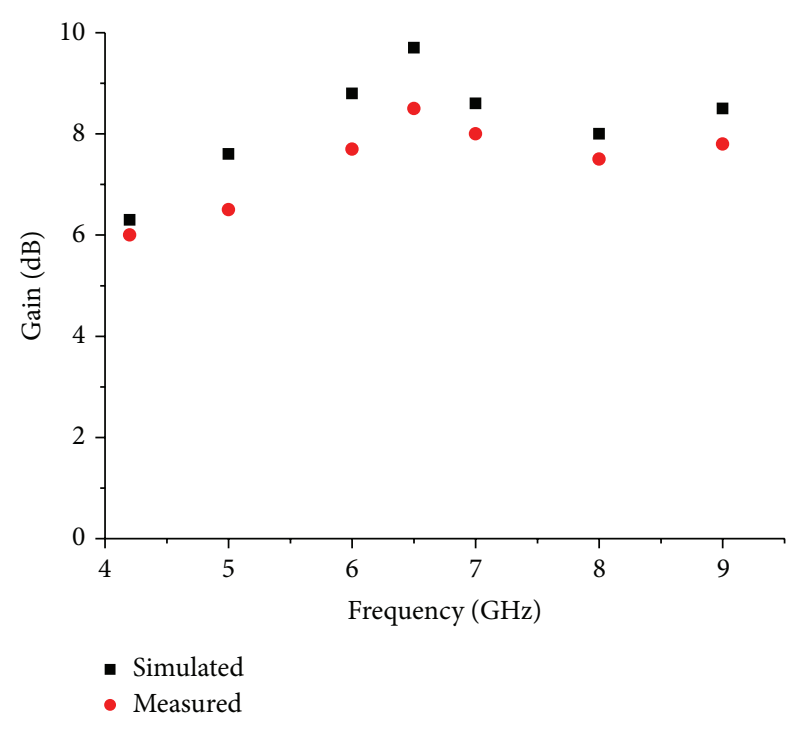

FIGURE 9: Simulated and experimental gain of proposed antenna.

The measured results indicate that the proposed antenna can work in the band of $4.2-9.2 \mathrm{GHz}$ with the average gain of $7 \mathrm{~dB}$. Therefore, it can be used as wideband antenna. The feeding way of proposed antenna adopts non-cross-feeding and feeds on long dipole, which can avoid introducing coaxial line. Thus, it can be widely applied to antenna design in integrated circuit system.

\section{Conflict of Interests}

The authors declare that there is no conflict of interests regarding the publication of this paper.

\section{Acknowledgments}

The authors would like to express their sincere gratitude to the funds supported by the Postdoctoral Science-Research Developmental Foundation of Heilongjiang Province (Grant no. LBH-Q12112). The authors would also like to thank CST Ltd., Germany, for providing the CST Training Center (Northeast China Region) at their university with a free package of CST MWS software.

\section{References}

[1] Y. J. Cheng and Y. Fan, "Millimeter-wave miniaturized substrate integrated multibeam antenna," IEEE Transactions on Antennas and Propagation, vol. 59, no. 12, pp. 4840-4844, 2011.

[2] X. Han, L. Juan, C. J. Cui, and Y. Lin, "UWB dual-polarized Vivaldi antenna with high gain," in Proceedings of the International Conference on Microwave and Millimeter Wave Technology (ICMMT '12), vol. 3, pp. 1-4, May 2012.

[3] T. Abeesh and M. Jayakumar, "Design and studies on dielectric resonator on-chip antennas for millimeter wave wireless applications," in Proceedings of the International Conference on Signal Processing, Communication, Computing and Networking
Technologies (ICSCCN '11), pp. 322-325, Thuckafay, India, June 2011.

[4] C. Run-Nan, Y. Ming-Chuan, L. Shu, Z. Xing-Qi, Z. XinYue, and L. Xiao-Feng, "Design and analysis of printed yagiuda antenna and two-element array for WLAN applications," International Journal of Antennas and Propagation, vol. 2012, Article ID 651789, 8 pages, 2012.

[5] S. Lin, G.-L. Huang, R.-N. Cai, and J.-X. Wang, "Novel Printed Yagi-Uda antenna with high-gain and broadband," Progress in Electromagnetics Research Letters, vol. 20, pp. 107-117, 2011.

[6] H. Wang, D.-G. Fang, B. Zhang, and W.-Q. Che, "Dielectric loaded substrate integrated waveguide (SIW) H-plane horn antennas," IEEE Transactions on Antennas and Propagation, vol. 58, no. 3, pp. 640-647, 2010.

[7] Q. Wu, R. H. Jin, and J. P. Geng, "A single-layer ultrawideband microstrip antenna," IEEE Transactions on Antennas and Propagation, vol. 58, no. 1, pp. 211-214, 2010.

[8] H.-R. Chuang and L.-C. Kuo, "3-D FDTD design analysis of a $2.4-\mathrm{GHz}$ polarization-diversity printed dipole antenna with integrated balun and polarization-switching circuit for WLAN and wireless communication applications," IEEE Transactions on Microwave Theory and Techniques, vol. 51, no. 2, pp. 374-381, 2003.

[9] S. Lin, S. Luan, Y. D. Wang et al., "A printed log-periodic tree-dipole antenna (PLPTDA)," Progress in Electromagnetics Research M, vol. 21, pp. 19-32, 2011.

[10] Z. Zhang, K. Wu, and N. Yang, "Broadband millimeter-wave quasi-Yagi antenna using Substrate Integrated Waveguide technique," in Proceedings of the IEEE Radio and Wireless Symposium (RWS '08), pp. 671-674, January 2008.

[11] E. Abdo-Sanchez, J. Esteban, T. M. Martin-Guerrero, C. Camacho-Penalosa, and P. S. Hall, "A novel planar log-periodic array based on the wideband complementary strip-slot element," IEEE Transactions on Antennas and Propagation, vol. 62, no. 11, pp. 5572-5580, 2014.

[12] H.-T. Hsu and T.-J. Huang, "A koch-shaped log-periodic dipole array (LPDA) antenna for universal ultra-high-frequency (UHF) radio frequency identification (RFID) handheld reader," IEEE Transactions on Antennas and Propagation, vol. 61, no. 9, pp. 4852-4856, 2013.

[13] G. A. Casula, P. Maxia, G. Montisci, G. Mazzarella, and F. Gaudiomonte, "A printed LPDA Fed by a coplanar waveguide for broadband applications," IEEE Antennas and Wireless Propagation Letters, vol. 12, pp. 1232-1235, 2013.

[14] M. N. A. Karim, M. K. A. Rahim, H. A. Majid, O. Ayop, M. Abu, and F. Zubir, "Log periodic fractal koch antenna for UHF band applications," Progress in Electromagnetics Research, vol. 100, pp. 201-218, 2010.

[15] C. Campbell, I. Traboulay, M. Suthers, and H. Kneve, "Design of a stripline log-periodic dipole antenna," IEEE Transactions on Antennas and Propagation, vol. 25, no. 5, pp. 718-721, 1977.

[16] R. Carrel, “The design of log-periodic dipole antennas," in Proceedings of the IRE International Convention Record, vol. 9, pp. 61-75, 1961. 

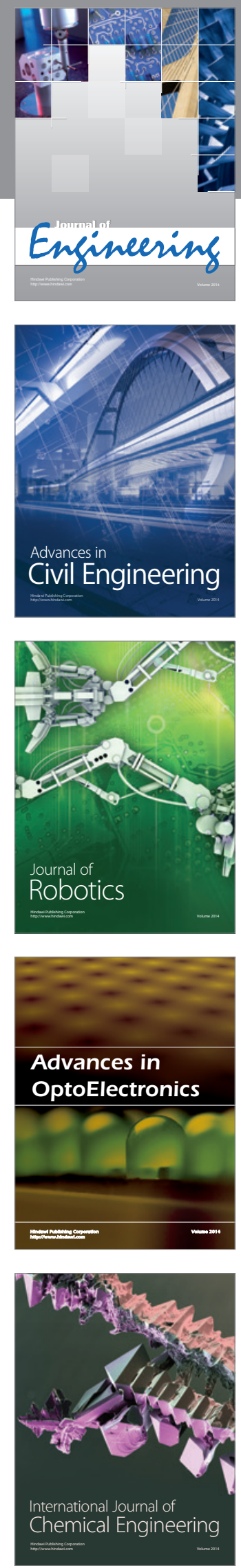

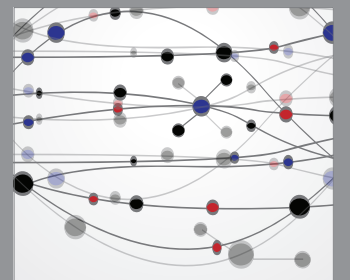

The Scientific World Journal
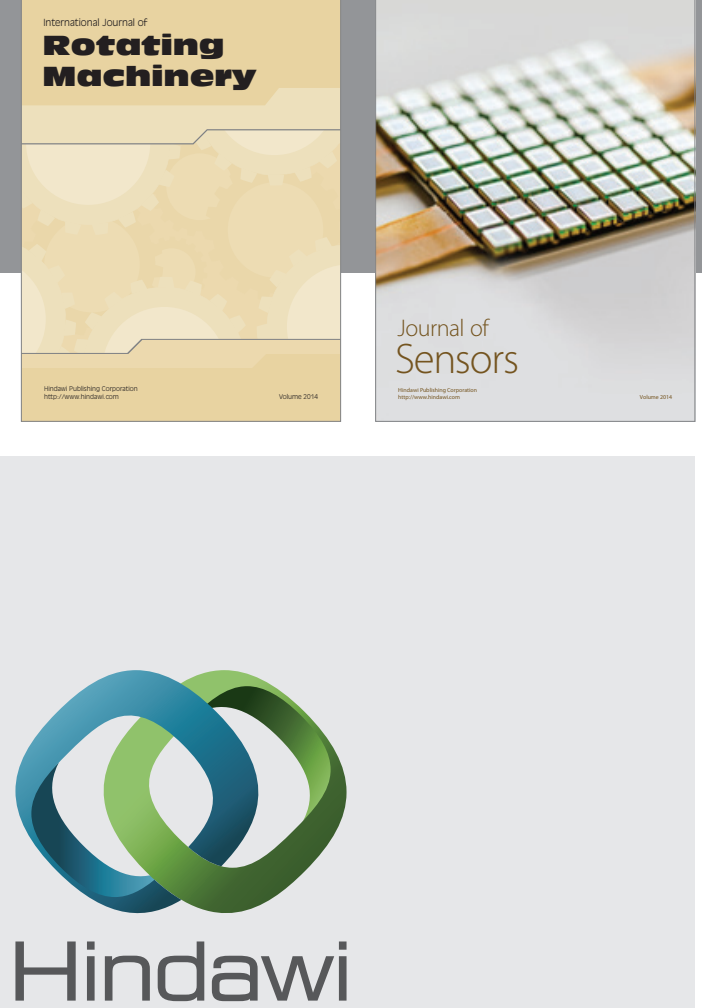

Submit your manuscripts at http://www.hindawi.com
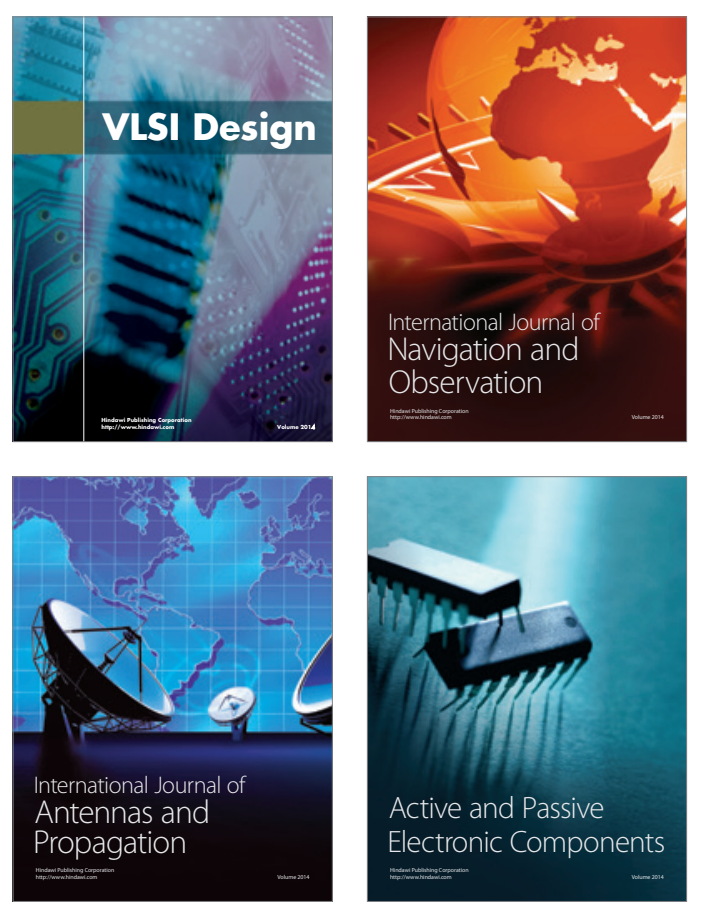
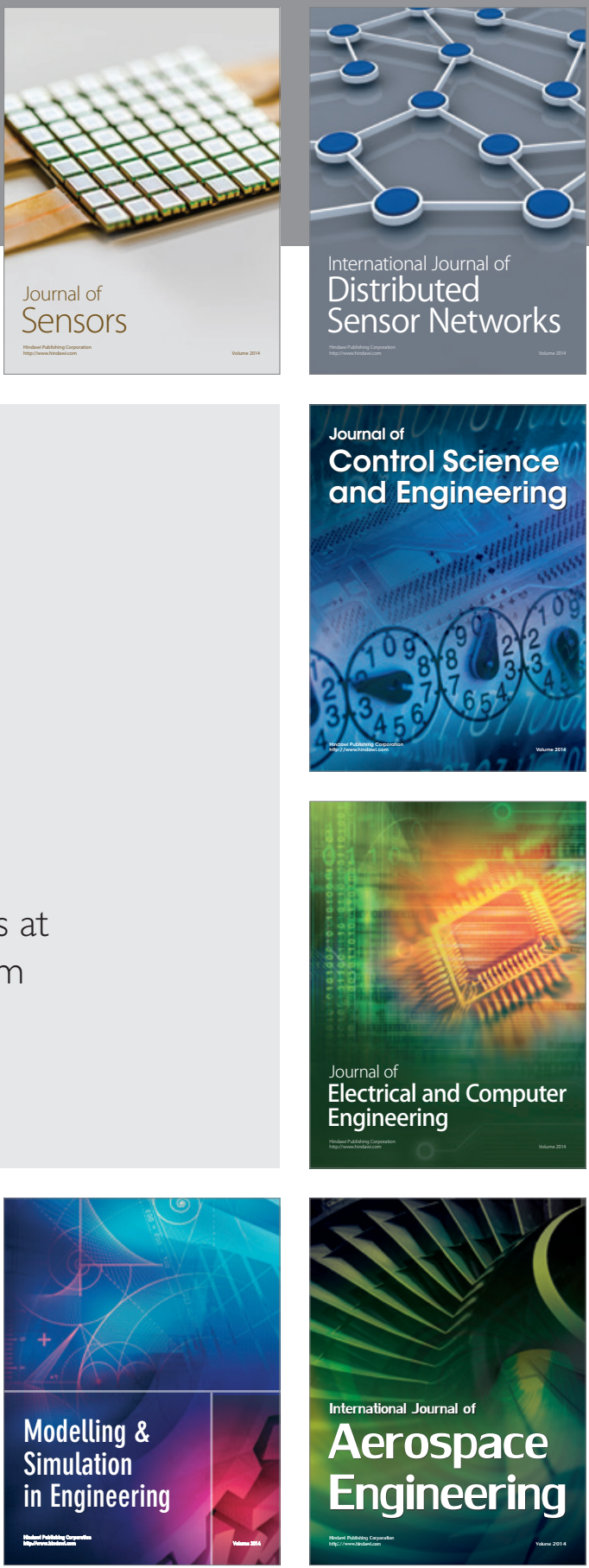

Journal of

Control Science

and Engineering
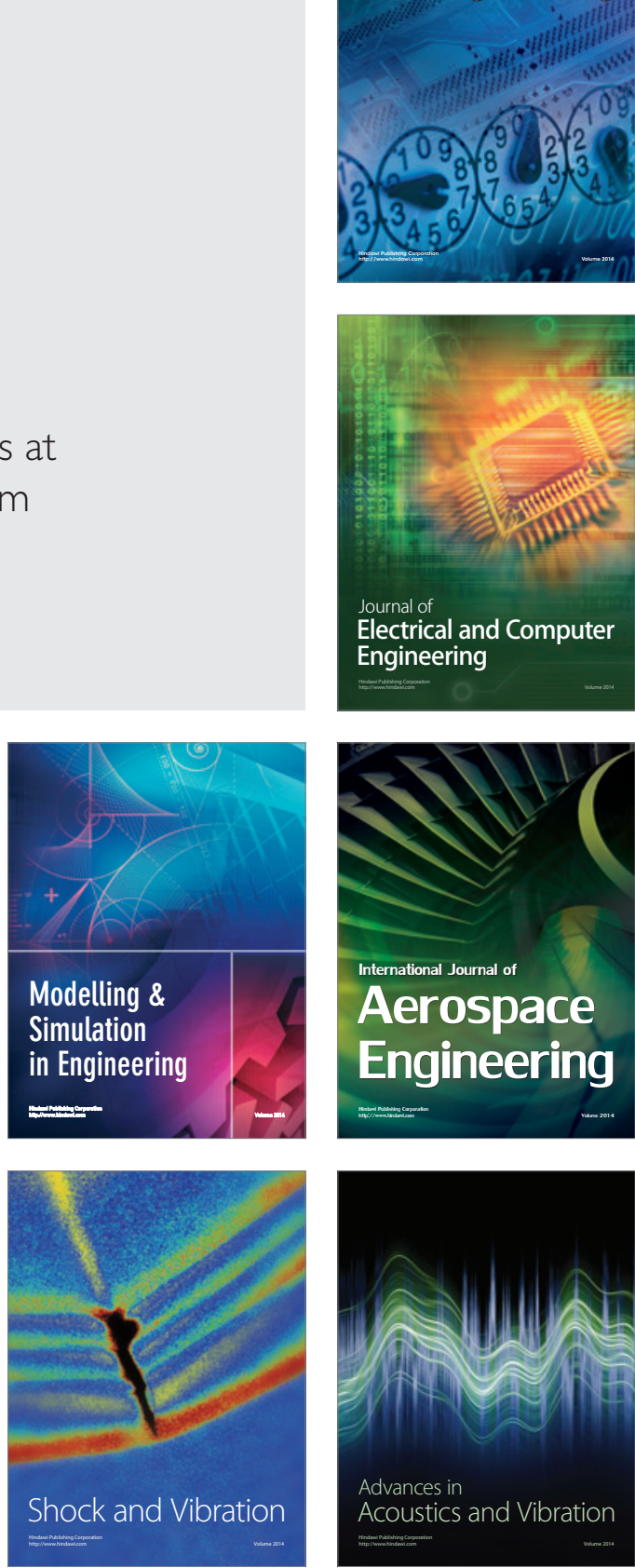